\title{
(息)
}

Citation:

Camoletto, RF and Sterchele, D and Genova, C (2015) Managing alternative sports: new organisational spaces for the diffusion of Italian parkour. Modern Italy, 20 (3). 307 - 319. ISSN 1353-2944 DOI: https://doi.org/10.1080/13532944.2015.1065237

Link to Leeds Beckett Repository record:

https://eprints.leedsbeckett.ac.uk/id/eprint/1627/

Document Version:

Article (Accepted Version)

The aim of the Leeds Beckett Repository is to provide open access to our research, as required by funder policies and permitted by publishers and copyright law.

The Leeds Beckett repository holds a wide range of publications, each of which has been checked for copyright and the relevant embargo period has been applied by the Research Services team.

We operate on a standard take-down policy. If you are the author or publisher of an output and you would like it removed from the repository, please contact us and we will investigate on a case-by-case basis.

Each thesis in the repository has been cleared where necessary by the author for third party copyright. If you would like a thesis to be removed from the repository or believe there is an issue with copyright, please contact us on openaccess@leedsbeckett.ac.uk and we will investigate on a case-by-case basis. 


\title{
Managing alternative sports:
}

\section{New organisational spaces for the diffusion of Italian parkour}

\author{
R. Ferrero Camoletto ${ }^{\mathrm{a}^{*}}$, D. Sterchele ${ }^{\mathrm{b}}$, C. Genova ${ }^{\mathrm{a}}$ \\ ${ }^{\text {a }}$ Department of Cultures, Politics and Society, University of Turin, Italy \\ ${ }^{\mathrm{b}}$ Institute for Sport, Physical Activity and Leisure, Leeds Beckett University, UK
}

\begin{abstract}
The article explores the encounter between parkour as an unstructured and culturally innovative practice, challenging both physical as well as organisational spaces, and UISP (Unione Italiana Sport per Tutti / Sport for All Italian Union) as a sport promotion body open to organisational and cultural experimentation. Drawing on a multi-method qualitative approach (analysis of documentary material, interviews and focus groups), we look at the role of UISP in the diffusion and legitimation of parkour within the Italian context, investigating the interplay between the cultural and organisational logics of both this new practice itself on the one hand, and the organisations that are trying to accommodate it on the other. The incorporation in a sport-for-all organisation like UISP provides traceurs with a safe and legitimised space, which is however 'loose' enough to maintain the fluidity of the practice. Nonetheless, by enabling the coexistence of different and competing definitions and uses of parkour, this fluid organisational space reproduces tensions among traceurs and weakens their voice in UISP's decision-making processes.
\end{abstract}

Keywords: parkour; space; organisation; cultural politics; youth.

\footnotetext{
* Corresponding author: Email: raffaella.ferrerocamoletto@unito.it.
} 


\section{Introduction}

Space is used, organised and performed in different ways by different sports. Whilst traditional mainstream sports tend to standardise space in order to enable comparisons and competitions, contemporary forms of physical activity - such as skateboarding, surfing, free-climbing - periodically emerge, aiming at enhancing bodily expressivity through creative and unconventional uses of space (Wheaton 2004). One of the most recent examples is parkour, which can be defined as the art of smoothly and efficiently moving from one point to another by creating one's own way through the urban space, turning its obstacles and constraints into opportunities to play (Bavington 2007).

Given their unstructured character and uncompetitive ethos, these 'new' 'alternative' sports ${ }^{1}$ tend not to develop through formal groups, governing bodies and official competitions. However, those organisations that use sport as a tool for social inclusion and active citizenship are more sensitive to the innovative potential of these practices and have recently tried to support their diffusion. Nonetheless, the relationship between structured, formal organisations and fluid, spontaneous 'sporting movements' entails the management of the challenging contradictions involved.

The investigation into the emergence and development of parkour in Italy ${ }^{2}$ provides an opportunity to explore the intersection between the cultural and organisational logics of both this new practice itself on the one hand, and the organisations that are trying to accommodate it on the other. To this aim, we will examine the role of UISP - Unione Italiana Sport per Tutti (Sport for All Italian Union), one of the main Italian sport-for-all bodies, in the diffusion and legitimation of parkour within the Italian context. At the same time, the challenge of incorporating parkour gives UISP an opportunity to further develop its transformation from a rigid and ideologically/politically oriented mass-organisation into a flexible and up-to-date sport-for-all provider, open to new/alternative sports. The analysis provides a more general insight into the processes of social change, between continuity and transformation, of the Italian sport system and its difficulties in structurally and culturally adapting to new forms of sporting citizenship, thereby becoming more capable of catering for the changing needs of its population. ${ }^{3}$

Notably, by reconstructing the stages of the (partial and still on-going) co-opting and incorporation ${ }^{4}$ of parkour within UISP, we will analyse the tensions and challenges of embedding an unstructured and culturally innovative practice into a formal organisation. On the one hand, by constructing a legitimate space for parkour and providing local access to 
the international coaching qualification ADAPT (Art du Déplacement and Parkour Teaching), UISP contributes to shaping the field of Italian parkour, thus unintentionally favouring certain actors and concepts of the practice over others. On the other hand, the fluid and unstructured nature of parkour contributes to reveiling and problematising the rigidity of the organisational logics that characterise even an innovative association like UISP, opening up an arena for the definition of its cultural politics in relation to youth participation, uses of urban space and community-building effects.

This article will thus explore the interplay between parkour as an unstructured and culturally innovative practice and UISP as a sport promotion association open to organisational and cultural experimentation. Adopting a multi-method qualitative approach, we will draw on the analysis of documentary material (websites, social networks, newspapers), informal interviews with UISP officials, individual in-depth interviews and focus groups with parkour practitioners - usually called traceurs - who took part (or deliberately did not) in ADAPT qualification courses for parkour instructors in 2012 and 2013.

We will firstly introduce the main characteristics of parkour, explaining how they challenge both physical as well as organisational spaces. Secondly, we will briefly outline how parkour developed in Italy and how it started to be supported or co-opted by sport-forall organisations. Thirdly, we will analyse the specific case of UISP and its attempt to create an innovative organisational space more suitable for unstructured practices like parkour. We will conclude by discussing the main implications of such an on-going process.

\section{The challenging nature of parkour: beyond physical and organisational boundaries}

The origins of parkour can be traced back to the 1980s in some deprived suburbs surrounding Paris (mainly Lisses and Evry), where a group of youngsters developed a way of moving through urban spaces by creating fluid pathways and overcoming obstacles (for an insider's reconstruction, see Edwardes 2007). ${ }^{5}$

In just a few decades, parkour has gained an extraordinary visibility in the global sportscape, thanks to its precocious mediatisation in blockbuster movies and documentaries, on internet video channels like Youtube, on websites and social networks (Gilchrist and Wheaton 2011, 2012; Stapleton and Terrio 2012). 
The extensive interdisciplinary academic literature triggered by the emergence of this new cultural phenomenon emphasises its 'subversive' (Bornaz 2008) or 'challenging' (Brown 2007) nature, able to transform perceptions and uses of space (Bavington 2007; Ameel and Tani 2011; Ameel and Tani 2012; Kidder 2012) and to increase a sense of selfmastering and self-efficacy (Saville 2008). Only a few studies have taken into account the impact of parkour on local policies and political agency (Atkinson 2009; Gilchrist and Wheaton 2011; Thorpe and Ahmad 2012).

The creative approach to physical space, mainly the urban environment, is a core aspect of the practice. Saville (2008) underlines the alternative use of the space challenging implicit conventional bodily rules and developing a different way to sensorially get in touch with the materiality of the urban context. This innovative sensuous contact with the city makes the traceur a new form of flâneur, capable of a playful and aesthetic relationship with the urban landscape, loosening up spaces (Ameel and Tani 2012). Traceurs progressively develop 'parkour eyes', an embodied skill which 'is not only about seeing possibilities in unexpected places, but also about seeing possibilities for attaching new and unexpected feelings to a place' (Ameel and Sirpa 2011, 7). Questioning the organisation of urban space 'by an array of material-spatially embedded power relations corresponding to the placement of fences, walls, stairs, ramps, and railings to organise flows of people, to control movement and to promote conformity to ideological categories and concepts of public order and “normal” behaviour' (Bavington 2007, 396), the city is reinterpreted not only as a playground for physical activities, but also as a text to be re-read and re-written: 'The city is not only a space [...] it is also a discourse' (Ortuzar 2009, 63). A key aspect of parkour is, then, 'the capacity to "deny evidences"', going beyond the discursive and ideological construction of the urban objects and spaces meanings (Bavington 2007, 397-398) and uncovering the plurality of spatial understandings and uses (Daskalaki et al. 2008).

In this article we aim to explore an interesting but overlooked feature: how parkour as a fluid and unstructured practice challenges not only physical spaces, but also organisational spaces ${ }^{6}$ traditionally shaped by mainstream sport cultures. If traceurs can rewrite the city as a discoursive space, what happens when they enter the sport field as a whole and a specific sport organisation in more detail? How and to what extent do they rewrite these organisational spaces? And how are they led to re-write their way of conceiving and practising parkour? Whilst on the one hand parkour may question traditional sport organisations, calling for organisational innovation and flexibility, on the other hand it also needs an organisational platform to promote in the wider audience (and potential market) its 
representation of respectability, safety and social utility. We analyse the institutionalisation of the Italian parkour scene ${ }^{7}$ at the intersection of actual and virtual places (governing bodies, associations and informal groups, competitions and contests, courses, videos, magazines and social media) where the values and skills of parkour are performed. The establishment of parkour as a symbolic and organisational field (Ojala 2014) is characterised by power relations, conflicts and fragmentation between the various actors involved, and differences in values, styles, skills and levels of commitment.

Parkour shares with other lifestyle sports (Wheaton 2004, 2013) an unstructured configuration and an uncompetitive ethos which escapes formal governing bodies (e.g. Federations, Leagues and Committees) focused on the management of traditional sports competitions. Traceurs tend to represent themselves as 'tribes' or 'crews', 8 i.e. small, informal, and relatively fluid groups, which eventually generate 'families', i.e. larger networks of different local crews. As we will see, the Italian parkour organisations, too, have gone through a germinal phase of informal gathering without a formal status; very few groups have chosen to maintain a totally informal configuration. Most of them gradually took on the formal status of 'amateur sport association' (Associazione Sportiva Dilettantistica, ASD) which gives access to public funds, sport facilities and insurance covera, resources that become necessary when a shift occurs from being a self-managed group of practitioners to gaining a wider visibility by offering introductory courses and tutorial activities to a larger audience of newbies. In a similar way to what has happened in other lifestyle sports (for snowboarding, see Coates et al. 2010), traceurs become actively involved in structuring their practice through the dialectics between linking themselves with more traditional sport organisations and creating alternatives to them.

However, parkour groups are not the only ones who take advantage of this shift towards a more formal setting. Due to its strong appeal to younger generations and more broadly to the contemporary social imagination, parkour has also attracted the attention of those organisations that use sport to promote social participation, which have rapidly acknowledged the potential of this emerging practice. In a similar way to other countries (Gilchrist and Wheaton 2011; Wheaton 2013) in Italy, too, sport-for-all organisations have progressively co-opted informal groups of traceurs and supported their growth, especially through the endorsement of cultural events involving parkour workshops and exhibitions and the management of parkour courses for beginners and of training packages for parkour instructors. 
Both the structured organisational forms of the sport-for-all associations and the fluid and spontaneous configuration of parkour as a lifestyle sport are challenged by their encounters and reciprocal impact: they both thereby are called to re-negotiate boundaries and rules in the definition of the spaces of the practice (outdoor or indoor?), of training (which courses?), of public performances (contests, exhibition or workshops?), of voice and involvement in decision-making processes within the sport organisation (freedom with marginality or formalisation with power?).

\section{The Italian way to parkour: history and geography of a practice}

The Italian sport system has a peculiar organisational structure, in which the government does not directly intervene in the management of sport, this role being played by an intermediary body, the Italian National Olympic Committee (CONI), in charge of managing the government financing (through the Ministry of Economy and Finance) and distributing funds (also through the monopoly of the sport betting system) to Sport Federations (and Associated Disciplines), Military Sport Clubs and Sport-for-all Organisations (Enti di Promozione Sportiva, EPSs). While Federations and Military Sport Clubs, under CONI supervision, run elite/high performance sports, EPSs endorse sport-for-all activities as a means for social inclusion and participation (Porro 1995; Buscarini 2008).

Born after World War II and formally acknowledged as institutional subjects of the sport system in 1974, EPSs represented the sporting vanguards of mass parties, whose hierarchical and rigid structure they replicated, gradually undertaking a surrogational function in the provision of sport for wellbeing and social inclusion which was overlooked by the Italian political institutions, and only focused on the promotion of elite sport through the CONI. The biggest EPSs - the Italian Sport Centre (Centro Sportivo Italiano, CSI) and the UISP - were created and supported by the Catholic and Communist parties respectively. Their stories were at length characterised by a double "collateralism” (Porro 2013), given their ancillary relationship with both the political system and the CONI, with more recent but still uncompleted attempts to interrupt such a symbiotic relationship after the end of the so-called Italian First Republic.

Nowadays, UISP is one of the main actors in the Italian sport system, with about 1,400,000 individual members, including various levels and forms of engagement (from 
sport instructors and street workers in social projects to simple sport practitioners or less involved members of some local clubs offering leisure services).

Founded in 1948, UISP has shown in its history a flexibility in balancing adaptation and change and progressively modifying its name (in 1978, from Unione Italiana Sport Popolare to Unione Italiana Sport per Tutti) ${ }^{9}$, its mission (from social cohesion and national identification to active citizenship and social participation) and its organisational configuration (from hierarchically-structured Discipline-Leagues and Areas, similar to CONI Federations, to a stronger role for local committees and the inclusion of new 'less institutionalised' forms of activities) (Porro 2013).

As well as other sport-for-all organisations, like AICS (Associazione Italiana Cultura e Sport - Italian Association Culture and Sport, founded in 1962) and CSEN (Centro Sportivo Educativo Nazionale - National Educational Sport Centre, founded in 1974), UISP has recently strategically worked at intercepting the new trends in body and sport cultures, with specific attention given to street sports and notably parkour as an emerging practice, as we will see in more detail in the next section.

Parkour has indeed a recent history in Italy, where the parkour scene developed in the middle of the 2000s, thanks to the sporadic and separate experiences of individual pioneers (who now tend to be in their thirties) progressively gathering in a nationwide network. A fundamental role was played by new technologies (initially email and websites, then blogs, social networks and video internet channels), as is usual in the diffusion of lifestyle sports (Gilchrist and Wheaton 2011). The key milestone was 2005, when in the same year the first Italian website devoted to parkour and the first web-based parkour network were created and the first national meeting of parkour was held, becoming a space for people to get in contact and practise together, thereby confronting, exchanging and learning from each other, building a sense of an emerging community. In the following five years, the Italian parkour scene took shape, increasing its dimensions and visibility, but also its fragmentation. The proliferation of local groups (with their own websites and events) and the persistence of internal tensions and rivalries tarnished the myth of a homogeneous and closely-knit community, despite some sporadic attempts to create a common platform. Some groups chose the way of professionalisation and spectacularisation, featuring as stuntmen in advertisements and happenings, whilst others started to create courses to induct younger cohorts increasingly interested in new and alternative urban practices. Therefore a demand for a 'safe-sport' representation of parkour emerged, entailing the need for both 
insurance covera and teaching credentials in order to ensure the quality of the courses for both beginners and instructors themselves.

Sport-for-all organisations entered this fragmented field by offering an organisational frame for individual and group membership, by endorsing parkour public events ${ }^{10}$ and by addressing the demand for teaching credentials through the promotion of training packages for parkour instructors.

UISP managed to incorporate into its organisation a large portion of the parkour scene: in 2013 about 70 parkour groups and 1,400 traceurs were formally affiliated, including some of the most active parkour groups in the national landscape. Despite its seemingly niche dimension, parkour has undergone a fast development within UISP when compared to other lifestyle practices, crossing the symbolic threshold of one thousand members in only two years (whilst it took six years for skateboarding memberships to grow beyond that number).

It is within UISP affiliated parkour associations that a strong stance was taken in the debate on the uncontrolled proliferation of courses held by instructors without any qualification. In 2010, four of the most important Italian parkour associations - namely Momu (Rome), Rhizai (Trani), Milan Monkeys (Milan) and ParkourWave (Bergamo) -, all UISP members, signed the 'Italian Manifesto of Parkour'11 as a potential new umbrella for the Italian parkour scene. The Manifesto aimed at defining an orthodoxy (listing as the core principles of parkour, 'the history of the discipline, founders and representatives, definition and sharing of values') and a legitimate way of transmission, identified in the ADAPT certification. ${ }^{12}$ Despite this document being presented as a space for 'an open debate with the Italian community' and as the expression of 'various realities (associations and informal groups) teaching and/or practising the discipline of parkour in the national context', its proposal has raised some critical reactions by groups of traceurs who support different visions of the practice, thus reveiling the ongoing struggle for authenticity within a field crossed by multiple identities as well as complex and unstable power relations. ${ }^{13}$

\section{Creating an undisciplined organisational space: the case of UISP}

UISP’s embracing approach to parkour can be interpreted as part of a broader cultural politics aimed at both marking a distinction from CONI's 'elite/performance sports', and 
gaining a hegemonic position in the endorsement of sport as a form of active citizenship, in competition with other sport-for-all organisations.

An emblematic case-study of UISP's distinctive strategy is represented by the project Spazio Indysciplinati (Undisciplined Space), whose name refers to both the challenging character of the practices involved and their failure to fit into any existing UISP Discipline-Leagues. Among these alternative practices, parkour holds a specific challenging potential because of its recent history, fast and successful diffusion and ongoing transformation. By intersecting with other UISP projects ${ }^{14}$ including various street activities (juggling, parkour, street theatre, capoeira, skateboarding), since 2010 Spazio Indysciplinati has progressively emerged as a cultural and organisational space as open and fluid as the kind of sport and bodily activities covered, cutting across the vertical structure of the Disciplines/Leagues ${ }^{15}$. In 2013, the platform gave birth to the educational project Percorsi Indysciplinati (Undisciplined Pathways), aimed at conducting workshops in ten Italian towns, representative of the different macro-areas (North-West: Turin, Bergamo and Genoa; North-East: Padua and Trieste; Central Italy: Reggio Emilia and Pisa; South: Barletta, Lanusei and Messina), engaging about 1,500 adolescents in unstructured activities like parkour, street-dance, hip-hop, skateboarding, snowboarding and juggling during the school-year 2013-14.

UISP showed that it aimed to position itself at the cutting edge not only by intercepting the new cultural trends outside, but also by changing its own associative and organisational pattern from within. As the presentation document of the project states:

For us this is an organisational, cultural and political challenge. It requires flexibility, imagination, elaboration, risk-taking. We must work in unusual, unknown and non-reassuring ways. [...] This means to redefine our organisational model and our devices (enrolment, communication, relational patterns, etc.) $\ldots{ }^{16}$

The cultural challenge is embodied in the core values of the project, which are the values of the new target addressed: people moving beyond sport-as-discipline boundaries, searching for freedom, autonomy, authenticity, aesthetic and environmental quality and sociability. A long and comprehensive range of activities is listed, to underline the adoption of an inclusive approach which is always at the forefront and open to what is new, emergent and unexpected. 
To come to terms with this new target of practitioners and activities, UISP also faces an organisational challenge. Indeed, despite being practised outside formal and structured spaces, times and organisations, these new activities are not 'disordered' since they follow a grass-roots, self-ruled and self-managed social and symbolic order within affinity groups under the guise of tribes and crews. They thereby require a new organisational model that skips the traditional patterns and creates a 'loose organisational space' (Ameel and Tani 2012).

This fluid and loose organisational form can be emblematically represented by the title of the 2012 Indysciplinati Convention, based on the metaphor of 'the shape of the water', since the latter takes the shape of its container. Spazio Indysciplinati is therefore planned to be 'a cross-cutting space, a dimension that welcomes every expression of physical movement in their unstructured and unconventional form, not ruled by predetermined norms, times and places' ${ }^{17}$

The UISP project document firstly describes this platform in its ideal aims and constitutive values, focusing on what makes this space differ from the traditional UISP system (which is structured into Leagues and Areas):

Spazio Indysciplinati is not a League because it is not structured, at least no longer than is needed; it is not an Area because it does not demarcate a field, since something would inevitably be left outside. It is a space, free and changeable, where it is possible to adapt in real time to the requests of a changing world, where activities and disciplines aim at experimenting in order to evolve and at freely self-managing. Therefore we can enter and exit from a model, enter and exit from a 'space' which provides only opportunities. It is a space that cuts across the different Leagues of activities, open and changeable, to be created time after time, able to intercept the expressive needs of young people and all those unstructured and undisciplined physical activities they practise. ${ }^{18}$

This organisational experimentation, however, is not perceived as an isolated experience, detached from and lacking the support (and legitimation) of the broader organisational context of UISP. On the contrary, Spazio Indysciplinati appears to be strongly embedded in the more general process of organisational experimentation inside UISP, as it emerges in the welcoming reactions of some Leagues representing the 
'established' organisational pattern. For instance, the president of the 'Traditional Sport and Games’ League declared in an interview:

We very strongly welcome the idea of creating a space open to all those undisciplined activities which would otherwise run the risk of staying out of the UISP world or to be caged into a single discipline while because of their very nature they are activities that cut across different Leagues and Areas. Therefore I believe that Spazio Indysciplinati provides a useful opportunity to reflect upon some troubling questions, first of all those related to the formal membership. As an example, many people revolve around our League who don't want to get involved in a structured activity but rather participate in our initiatives only to have fun, to play and stay with other people. If they were bound by a membership card or by a pre-defined calendar, they would drop out. ${ }^{19}$

Finally, the organisational challenge provided by Spazio Indysciplinati also represents a strategic resource for UISP not only to intercept new trends and new targets, but also to mark its distinction from the institutional sport-system lead by CONI and its bureaucratic structures. In so doing, UISP claims the advantage of being a sport-for-all organisation with a lighter and more flexible structure able to adapt to the changing sport scenario, as highlighted by the national director of UISP's Sector for Educational Policies:

The sport-system usually changes very slowly and with great difficulty. We are not a Federation, thus we can try to be more adaptable and ready. We must try to be undisciplined in the strict sense; to exit from the rules to then re-enter the UISP-system under new guises. ${ }^{20}$

However, despite the cultural and organisational flexibility at the core of the project, some controversial elements emerge from the analysis of the policies and activities endorsed by Spazio Indysciplinati, and notably the specific position of parkour within this organisational space.

Indeed, parkour has progressively acquired a central role in UISP’s cultural politics of incorporation of alternative street sports, as is witnessed by the strong stance taken in signing the agreement with Parkour Generations, the UK-based parkour association that provides the ADAPT assessment system to train parkour instructors. Thanks to this 
agreement, UISP held the first Italian ADAPT courses level 1 (for assistant coaches) in 2012, 2013 and 2014 and level 2 (for coaches) in 2013 under the supervision of instructors from Parkour Generations. By presenting the ADAPT programme as the only qualification acknowledged by the founders and which thereby embodies the authentic version of the discipline, UISP endorsed the interpretation preferred by the promoters of the aforementioned Italian Manifesto of Parkour, thus becoming a core actor in the process of institutionalisation of Italian parkour. Within the vision of ADAPT's supporters, indeed, parkour is represented as being under the threat of commercialisation and commodification, as stated by the main UISP's Italian instructor on the first ADAPT course level 1:

I was and I remain strongly convinced of the necessity to import ADAPT certification in Italy. [...] Criticism [of ADAPT] is based on superficial arguments by those who believe that this approach will cage parkour freedom. A false issue. ADAPT certification, the only one internationally acknowledged, protects practitioners from the crowd of proliferating instructors riding the wave without the appropriate training ${ }^{21}$.

Here a tension emerges between the flexibility in blurring the organisational boundaries of the practice on the one hand, and the risk of sheltering the discipline behind a strict definition of philosophical (which inspiring values and principles) and physical (which legitimate moves) boundaries on the other. Hence, by hosting and promoting ADAPT courses, Spazio Indysciplinati becomes a battleground for the hegemonic position in defining not only how parkour should be taught, but also what parkour really is. This fluid organisational space appears as a container which does not aim at shaping its content, but rather incorporates different and coexisting ways of doing parkour, leaving room for their potential intersection and reciprocal hybridisation.

The official position of UISP itself in this internal struggle for authenticity is not clear, leaving glimpses of ambivalence. While ADAPT courses emphasise the disciplinary and selective side of parkour (by insisting on physical conditioning, discouraging acrobatic moves and flips, and qualifying as coaches only tough and expert practitioners), other UISP-sponsored events and festivals such as Krap Invaders ${ }^{22}$ or Jambo include parkour together with other street sports and arts, valuing freestyle experimentation and creativity and promoting a more playful sport-for-all participation, but also opening the way for competitive contests. 
The Jambo Freestyle Festival $2014^{23}$ provides an emblematic example of the difficulties for UISP in attempting to manage a multiple space - including a main stage devoted to contests; a stand hosting free and open workshops; a round table comparing three different experiences (Denmark, Belgium and Italy) of parkour as a participatory practice - with competing cultural and organisational logic: elite/competitive vs inclusive/playful/educational.

Unsurprisingly, the official involvement of UISP in the Jambo Festival has raised some critical voices from parkour groups affiliated to UISP whose members endorse the more rigorous and less spectacularised version of the practice diffused through the ADAPT courses. Denouncing the ambivalent position of UISP, one of them explains:

The coexistence of different understandings of parkour within UISP is OK. It becomes a problem when UISP makes schizophrenic choices clearly led by political and commercial logics; this is not good, as in the case of Jambo, that really pissed us off. [...] The shape of the event defines the meanings that you convey. [...] Jambo includes forms of competition and exhibition. [...] One thing is that different souls coexist within UISP, another is that UISP endorses only one soul [...]. (phone interview, May 2014)

Nonetheless, other groups affiliated to UISP give different interpretations, as exemplified by this traceur involved in the Jambo Festival despite opposing the spectacularisation of parkour:

We are not joining the Jambo for the contest; UISP is giving us a space to involve various parkour associations in holding a three-hour workshop for those who want to try parkour instead of staying on the main stage to watch other people’s jumping exhibition. Last year I didn't like it [...] it wasn’t nice because it didn't give the guys the chance to try, many people just came and watched the show... but I think with this idea of a double space they have solved the problem. (on-line interview, May 2014)

This clearly shows how the attempt to create flexible and less-defined organisational spaces makes them also ambivalent (or rather polysemic) and generates conflicting reactions, adding further complexity to the relational and communicational management of this organisational challenge. 
A further controversial aspect concerns the tension between the cultural and the structural position of parkour within the UISP structure. Whereas in the rhetoric of UISP conventions and media releases parkour is assigned a central and leading role in the innovation of the organisation's cultural policies, its structural position (its membership being classified outside the main Leagues/areas, within the residual and miscellaneous category of New Activities ${ }^{24}$ ) runs the risk of producing weakening and marginalising sideeffects, disempowering both its potential innovative impact on UISP organisation as a whole and its actual voice in the organisation's decision-making processes. Acknowledging such a risk, some practitioners are exploring the possibility of creating a sort of 'parkour federation' to achieve a stronger position in power relations within both UISP and the sports field as a whole ${ }^{25}$.

\section{Conclusions}

Our focus on both the cultural and organisational dimensions of Italian parkour has proved to be a fruitful perspective from which to explore the complexity of this practice's institutionalisation. Whilst parkour implies a challenge to normative and conventional understandings and uses of physical places, its interpretative flexibility extends to re-tracing the boundaries of cultural and organisational spaces.

The case of the promotion of parkour within the associative network of UISP shows how both the boundaries of cultural identities and organisational forms are stretched. Moreover, similarly to what happens in other realms of Italian society (for instance, in the political field, see Bordignon and Ceccarini 2013), it renveils the tensions and contradictions involved in any attempt to promote structural and cultural changes within a system. This applies to both UISP, in its ambivalent role of innovative actor which is nonetheless also formally institutionalised within the Italian sport system, and the groups of traceurs, in their relationship with UISP specifically and with the whole Italian sport system more generally.

UISP has created and supported a 'loose space' (Ameel and Tani 2012) such as Spazio Indysciplinati to allow parkour and other street sports/arts to maintain their creativity and fluidity both in the accessing and the practising of the activity. In so doing, UISP itself seems to adopt 'parkour eyes' (Ameel and Sirpa 2011) in looking at traditional 
organisational patterns not only as obstacles to overcome, but also as resources that stimulate inventive organisational practices.

On the other hand, by opening the door for the ADAPT qualification programme to enter the field of Italian sports organisations, UISP has taken up a strong position in the struggle for parkour authenticity: gaining ADAPT qualifications, together with UISP membership, currently acquires a hegemonic cultural meaning within the Italian parkour community. In the contested field of Italian parkour, UISP supports ADAPT courses in becoming a space for defining and distributing 'authentic' subcultural capital (Wheaton and Beal 2003) and therefore attributing hierarchically-ordered insider statuses within the Italian (and international) parkour community.

The position of UISP in the parkour battleground illustrates the ambivalences and tensions of the process of institutionalisation of alternative sports. Whilst research literature has focused on the negative effects of sportisation in neutralising the oppositional character of these sports, the UISP case study provides a more complex understanding of these processes. On the one hand, those UISP members supporting the adoption of the ADAPT programmes claim the need to safeguard the authenticity of parkour from being exploited by commercialisation and spectacularisation. On the other hand, other traceurs affiliated to UISP point to the importance of 'keeping it free', defending parkour's openness to individual interpretation and thereby to an inherent pluralism of cultural and organisational practices.

The incorporation in a sport-for-all organisation like UISP can represent for the Italian parkour scene a particular way to maintain an oppositional stance. However, the coexistence within UISP of different and competing definitions and uses of parkour leaves room for an internal dialectic between the multiple ways of inhabiting architectural, sociocultural and organisational spaces.

\section{References}

Ameel, L., and S. Tani. 2011. "Everyday Aesthetics in Action: Parkour Eyes and the Beauty of Concrete Walls.” Emotion, Space and Society 10 (1): 30-40.

Ameel, L., and S. Tani. 2012. "Parkour: Creating Loose Spaces?” Geografiska Annaler: Series B, Human Geography 94 (1): 17-30.

Atkinson, M. 2009. "Parkour, Anarcho-Environmentalism, and Poiesis.” Journal of Sport \& Social Issues 33 (2): 169-194.

Bavinton, N. 2007. "From Obstacle to Opportunity: Parkour, Leisure, and the Reinterpretation of Constraints.” Annals of Leisure Research 10 (3-4): 391-412. 
Benasso, S., and L. Stagi. 2013. “Traces of Urban Bodies.” Lo Squaderno 27: 9-15.

Bennett, A. 1999. "Subcultures or Neo-tribes? Rethinking the Relationship Between Youth, Style and Music Taste.” Sociology 33 (3): 599-617.

Bordignon, F. and Ceccarini, L. 2013. "Five Stars and a Cricket. Beppe Grillo Shakes Italian Politics.” South European Society and Politics, 18 (4): 427-449.

Bornaz, N. 2008. "Parkour: l'art de subvertir le rapport à l'espace public." http://biblio.recherche-action.fr.

Brown, N. 2007. "The Art of Displacement. Parkour as a Challenge to Social Perceptions of Body and Space.” http://www.parkourgenerations.com/article/art-displacement.

Buscarini, C. 2008. "Le organizzazioni del settore dello sport: un quadro generale d'analisi e una possibile classificazione economico-aziendale.” Quaderni monografici Rirea, 72: $1-64$.

Coates, E., B. Clayton, and B. Humberstone. 2010. “A Battle for Control: Exchanges of Power in the Subculture of Snowboarding." Sport in Society: Cultures, Commerce, Media, Politics 13 (7-8): 1082-1101.

Daskalaki, M., A. Stara, and M. Imas. 2008. “The 'Parkour Organisation': Inhabitation of Corporate Spaces.” Culture and Organization 14 (1): 49-64.

Donnelly, M. 2006. "Studying Extreme Sports: Beyond the Core Participants.” Journal of Sport and Social Issues 30 (2): 219-224.

Edwardes, D. 2007. "Parkour.” In Berkshire Encyclopaedia of Extreme Sports, edited by Booth D., and H. Thorpe. Great Barrington, MA: Berkshire Reference Works, 233236.

Gilchrist, P., and B. Wheaton. 2011. "Lifestyle Sport, Public Policy and Youth Engagement: Examining the Emergence of Parkour." International Journal of Sport Policy and Politics 3 (1): 109-131.

Halford, S. 2004. “Towards a Sociology of Organizational Space.” Sociological Research Online 9 (1), http://www.socresonline.org.uk/9/1/halford.html.

Kidder, J.L. 2012. "Parkour, The Affective Appropriation of Urban Space, and the Real/Virtual Dialectic.” City \& Community 11 (3): 229-253.

Leone, M. 2010. "Semiotica del parkour.” In Semiotica dello sport, edited by Cervelli P., L. Romei, and F. Sedda. Rome: Edizioni Nuova Cultura, 208-224.

Ojala, A.L. 2014. "Institutionalisation in Professional Freestyle Snowboarding. Finnish Professional Riders’ Perceptions.” European Journal for Sport and Society 11 (2): 103-126.

Ortuzar, J. 2009. "Parkour or l'art du deplacement: a Kinetic Urban Utopia.” TDR/The Drama Review 53 (3): 54-66.

Porro, N. 1995. Identità, nazione, cittadinanza. Sport, società e sistema politico nell'Italia contemporanea. Roma: SEAM.

Porro, N. 2013. Movimenti collettivi e culture sociali dello sport europeo. Le stagioni della sportivizzazione. Acireale-Roma: Bonanno.

Salome, L. 2010. "Constructing Authenticity in Contemporary Consumer Culture: the Case of Lifestyle Sports.” European Journal for Sport and Society 7 (1): 69-87.

Saville, S.J. 2008. "Playing with Fear: Parkour and the Mobility of Emotion.” Social \& Cultural Geography 9 (8): 891-914.

Stapleton, S., and S. Terrio. 2012. "Le Parkour: Urban Street Culture and the Commoditization of Male Youth Expression.” International Migration, 50 (6): 18-27.

Straw, W. 1991. "Systems of Articulation, Logics of Change: Communities and Scenes in Popular Music.” Cultural Studies 5(3): 368-388.

Thorpe, H., and B. Wheaton. 2011. "'Generation X Games', Action Sports and the Olympic Movement: Understanding the Cultural Politics of Incorporation.” Sociology 45 (5): 830-847. 
Thorpe, H., and N. Ahmad. 2013. "Youth, Action Sports and Political Agency in the Middle East: Lessons from a grassroots Parkour Group in Gaza.” International Review for the Sociology of Sport. (published online 18 June 2013) doi: $10.1177 / 1012690213490521$.

Wheaton, B., and B. Beal. 2003. “'Keeping It Real’: Subcultural Media and the Discourses of Authenticity in Alternative Sports.” International Review for the Sociology of Sport 38 (2): 155-176.

Wheaton, B., ed. 2004. Understanding Lifestyle Sport: Consumption, Identity and Difference. London: Routledge.

Wheaton, B. 2013. The Cultural Politics of Lifestyle Sports. London: Routledge.

\footnotetext{
Notes

${ }^{1}$ We use the term "alternative" or "new" in its etic definition (cfr. Wheaton 2004; 2013) and in its emic use as a claim for authenticity and distinction by the actors involved.

2 The development of parkour in Italy is still an overlooked issue within the social sciences: for a sociosemiotic analysis see Leone 2010; for an introductory reflexive contribution to the Italian audience, see Benasso and Stagi 2013.

${ }^{3}$ An interesting parallel could be drawn with the recently emerged Five Star Movement and its controversial attempt to develop innovative forms of political action and participation both within and against the established system (Bordignon and Ceccarini 2013).

${ }^{4}$ For a broader analysis of the incorporation process of action sports within the Olympic movement, see Thorpe and Wheaton (2011).

${ }^{5}$ As Gilchrist and Wheaton $(2011,127)$ point out, the reconstruction of the history of an emerging practice, implying the definition of its authenticity, is a battleground for different conflicting voices. Parkour is not exempt from this struggle, as we will show when drawing the chronicle (defining key phases and actors) of the its development in Italy.

${ }^{6}$ The concept of 'organisational space' is used here metaphorically (for different uses, see Halford 2004).

${ }^{7}$ We adopt the concept of scene (Straw 1991) to highlight the interconnection of contextual, structural, social and cultural dimensions of parkour as a practice.

${ }^{8}$ Here we follow traceurs' use of 'tribes' and 'crews' as synonymous, but while the former is more conceptually and academically defined (Bennett 1999), thereby becoming an etic label, the latter derives from street cultures, being a more emic expression.

${ }^{9}$ That is from Italian Union Popular Sport to Italian Union Sport For All.

${ }^{10}$ See, for example, the CSEN parkour national meeting hosted within the Festival of Fitness, the AICS Rome Parkour Day or UISP Sport Days.

${ }^{11}$ Accessed on 15/03/2014 from: https://www.facebook.com/manifestoitalianodelparkour.

12 The presentation of the ADAPT programme (www.adaptqualifications.com) is consistent with the worries expressed in the Italian Manifesto: 'The ADAPT Programme of qualifications was created as a response to the rapid and widespread growth of the discipline of parkour around the world, which in turn led to people attempting to imitate the movements of the art without adequate training, understanding and/or preparation. [...] The ADAPT qualifications ensure that any individual who wishes to coach others in the art will do so in a knowledgeable, professional, competent and safe manner. The global network of ADAPT coaches also gives a new coach an existing resource of highly experienced coaches and coaching bodies to support him or her in their development as a coach. [...] To receive an ADAPT Instructor Qualification is to be approved to teach the discipline of parkour/art du déplacement by the foremost practitioners and teachers in the world, including the original Yamakasi and the traceurs from Lisses, Paris - the birthplace of parkour.'

${ }^{13}$ For the purpose of this article, we have only partially adopted a post-subcultural analytical framework. . See Wheaton and Beal (2003), Donnelly (2006), and, more recently, Salome (2010).

${ }^{14}$ The street-workers course Lampi \& Impronte dello Sport di Strada (Thunders \& Tracks of Street Sport) in 2010-2011; the project Contamin-Azioni (Contamin-Actions) in 2011; the Krap Invaders Freestyle Festival in 2011 and 2012.

${ }^{15}$ Spazio Indysciplinati is managed by a steering group called FEI - acronym for the three UISP sectors of Formazione (Training), Politiche Educative (Education Policies) and Innovazione e Sviluppo (Innovation and Development).

${ }^{16}$ Accessed on 16/03/2014 from: http://www.uisp.it//nazionale/?contentId=1898.

${ }^{17}$ Ibid.

18 Ibid.

${ }^{19}$ Accessed on 16/03/2014 from: http://www.uisp.it//nazionale/?contentId=1897.
} 
${ }^{20}$ Accessed on 17/03/2014 from: http://www.uisp.it//nazionale/?contentId=1860.

${ }^{21}$ Accessed on 17/03/2014 from: http://www.uisp.it/nazionale/extra/archivio_newsletter/preview_uispress.php?id _newsletter=62\&newsletter_type=uispress\#articolo14.

22 See their websites: www.krapinvaders.com.

${ }^{23}$ In the website http://thejambo.it/ (accessed on 26/05/2014) the different logics are presented as coexisting and complementary, not as competing: 'Try and learn the action sports // Partake the contests // Enjoy the shows'.

${ }^{24}$ A different organisational strategy was adopted to co-opt skateboarding, which was assigned a specific activity code within the pre-existing Skating League.

${ }^{25}$ In September 2014 an assembly of all the UISP-affiliated parkour association was held in Bologna, resulting in the creation of a Steering Committee involving some traceurs representative of the main geographical macro-areas and of different positions in the parkour scene. 